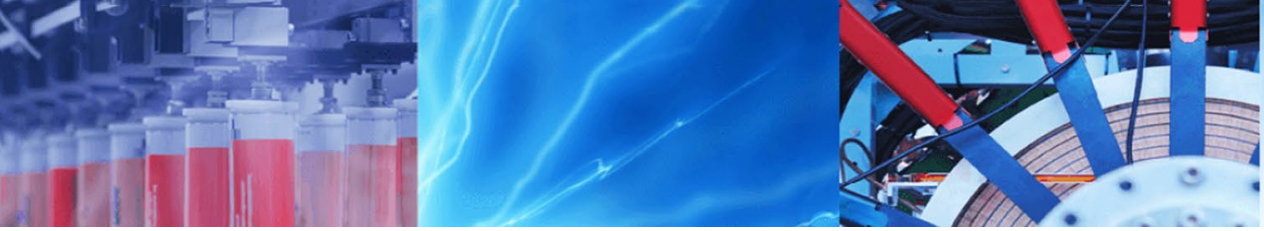

Research Article

\title{
Effect of Ti addition holding time on casting quality and mechanical properties of A356 alloy
}

\author{
Mikdat Gurtaran ${ }^{1} \cdot$ Muhammet Uludağ $^{1}$
}

Received: 13 June 2020 / Accepted: 8 October 2020 / Published online: 16 October 2020

(c) Springer Nature Switzerland AG 2020

\begin{abstract}
Bifilms are casting defects that occur due to the incorporation of surface oxide film into the melt. Thus, they act as a crack in the liquid. Once they remain in the structure, they decrease mechanical properties owing to their negative effect on porosity formation. One of the most fundamental problems to be avoided in this frame is the reduction of the bifilms or the cleaning of the liquid metal to prevent the porosity formation. In this study, A356 (Al-7Si-0.3 Mg) alloy was used. AlTi5B1 master alloy was added as a grain refiner. The effect of Ti on casting quality and mechanical properties changes by holding time was evaluated. The results were examined statistically by Weibull analysis. It was found that the presence of bifilms can be reduced as holding time increases after adding Ti. The tensile properties were increased as the holding time increased. Additionally, the optimum holding time may be $40 \mathrm{~min}$ after Ti addition for high casting quality and good mechanical properties.
\end{abstract}

Keywords A356 alloy · Grain refinement · Holding time · Mechanical properties · Casting quality

\section{Introduction}

Bifilms are casting defects that occur due to the incorporation of surface oxide film into the melt. Thus, they act as a crack in the liquid. Once they remain in the structure, they decrease mechanical properties [1-7]. On the other hand, hydrogen has always been blamed for the reduction of mechanical properties. It has been emphasized that the removal of hydrogen from the melt by degassing would reduce the porosity and thus improve the mechanical properties [8,9]. However, Campbell and Dispinar [10, 11] carried out several works on the mechanism of porosity formation and it has been shown that dissolved hydrogen is not the main factor but only a trigger. As is known, Al alloys can easily form oxides during casting. Bifilms are formed by entrainment of oxide films such as the use of poor feed systems and turbulence during casting into the melt [12]. Campbell [13] describes the effect of oxide films on porosity formation by three mechanisms:

1. Gas pressure within the folded oxide films

2. The negative pressure which occurs during solidification (shrinkage)

3. Dendrite arms that grow during solidification

The type of oxide that may form on the surface of liquid aluminum can be in three structures: amorphous, young and old [3]. Amorphous is in nanoscale which is the one instantly forms in milliseconds. Young oxide is the crystalline form in micrometer thickness which is also known as $\gamma-\mathrm{Al}_{2} \mathrm{O}_{3}$. Old oxide is the $\alpha-\mathrm{Al}_{2} \mathrm{O}_{3}$ which is corundum. The type of oxide that may be present in the final microstructure significantly determines the casting quality. As can be expected, the older and the thicker the oxide predominantly decreases the mechanical properties. Tiryakioglu

Muhammet Uludağ, dr.uludagm@gmail.com; muhammet.uludag@btu.edu.tr| ${ }^{1}$ Metallurgical and Materials Engineering, Bursa Technical University, 16310 Bursa, Turkey. 
et al. [7] showed that the tensile strength, hardness and elongation values of the $\mathrm{Al}-7 \mathrm{Si}-0.6 \mathrm{Mg}$ were greatly reduced by bifilms. During the transfer of the molten metal from the crucible, new bifilms are formed in a finer structure than the old bifilms. These are called young bifilm and they act mechanical properties negatively like young bifilms [14]. Dispinar and Campbell [10,11] quantified the bifilm content by a reduced pressure test. The measurement was based on the maximum length of pores as an indication of bifilm length which was named as "bifilm index":

$B_{l}=\sum$ maximum length of pores

Dispinar [12] investigated the correlation between bifilm index and mechanical properties. It was found that as the bifilm index was increased, tensile properties were decreased linearly.

Uludağ [15] studied the porosity formation mechanism of bifilms in three different alloys (A356, A413 and A380.1) that have different solidification range and morphology. In A356 alloy, which has dendritic and eutectic morphology [16], bifilms are trapped between the dendrite arms. In A413 alloy, the planer growth of eutectic morphology pushes the bifilms into the last region to solidify, resulting in large size pores. A380.1 alloy contains two different eutectic phases alongside the dendritic structure. Therefore, some of the bifilms are trapped between the dendrite arms and some remain in the two remaining eutectic liquids, thus, easier for bifilms to open up at three different solidification steps.

The use of aluminum and its alloys is increasing day by day in many critical applications [17]. Many works have focused on the improvement of performance by various alloying element additions [6]. Nevertheless, one of the most fundamental problems to be avoided is the reduction of the formation of bifilms or the cleaning of the melt from bifilms in order to increase mechanical properties [18]. Once the melt is free from bifilms, more consistent and reproducible properties can be established.

Parameters such as degassing and mold design play an important role in preventing or eliminating bifilms. Pouring basin, sprue, runner systems and ingate has to be designed to prevent the formation of turbulence during filling. The optimized mold design works perfectly for the melt that contains no bifilms. Thus, the second most important parameter becomes the removal of bifilms from the melt. This can be performed by degassing operations. The rising of inert bubbles through the melt attaches to the bifilms and collects them to the surface to be removed by skimming.[6, 19-21]. Yorulmaz [22] had shown the efficiency of degassing by balloon and feather analogy. Dispinar [12] had shown that after degassing, the mechanical properties were increased regardless of the hydrogen content of the melt. It was shown that the effect of bifilms on mechanical properties can also be quantified by Weibull analysis [4, 23-25].

To achieve better feeding and fluidity, various master alloys are added to the alloy in the liquid state. While strontium is generally preferred for Si modification and eutectic temperature depletion [26], Ti is added for grain refinement [27, 28]. Mohanty and Gruzleski [29]] characterized that the grain refinement mechanism of the three $\mathrm{Ti}$ master alloys ( $\mathrm{Al}-\mathrm{Ti}, \mathrm{Al}-5 \mathrm{Ti}-\mathrm{B}$ and $\mathrm{Al}-\mathrm{B}$ ) in the $\mathrm{A} 356$ alloy. On the other hand, Tondel [30] first show the improved equiaxed globular structure by $\mathrm{Al}-\mathrm{B}$ grain refinement. Later, Dispinar [31] and Uludağ [32] studied Al-B additions and showed that feed ability was improved significantly and pore formation was localized in A356 alloy. Additionally, the effect of rare earth elements ( $L a$ and $\mathrm{Ce}$ ) on the mechanical and microstructural properties of $\mathrm{A} 357$ was described by Jiang et al. [33]. It was demonstrated that the optimum addition is $0.2 \mathrm{wt} \%$ to achieve the best mechanical properties with the most acceptable particle size (a-Al primary phase and eutectic silicon particles) and eutectic Si morphology. Besides the traditional techniques for casting, a novel technological system, the expendable pattern shell casting process with vacuum and low pressure (EPSCVL), was also tried by Jiang et al. [34] to clarify the internal casting quality of A356 alloy produced under the parameters such as gas flow rate, vacuum level, and gas pressure. It was concluded that the EPSC-VL process has considerable advantages in mechanical properties compared to other types of pattern shell castings (under gravity and lost foam castings). Similar work on the Al-matrix composite reinforced by nano-sized $\mathrm{SiC}$ particles was presented by Zhu et al. [35]. In the study, Al6082 alloy was produced with high mechanical properties thanks to the $\mathrm{SiC}$, which was uniformly distributed by stir casting method.

In this study, the Al5TiB1 grain refiner was added to A356 (Al-7Si-0.3 Mg) alloy to investigate the durability of grain refiner on both melt quality and mechanical properties [36]. Reduced pressure test and tensile samples were collected at certain time intervals and the statistical analyses were performed. The main focus of the study is to clarify the holding time effect on the porosity, which plays a vital role in the mechanical and microstructural properties of Al alloys, and to describe the needs for excellent results for future studies.

\section{Materials and methods}

Primary A356 alloy was used in this study. The chemical composition is given in Table 1. 
Table 1 Chemical composition (in wt\%) of the A356 alloy used in the study

\begin{tabular}{lllllllll}
\hline Alloy & $\mathrm{Si}$ & $\mathrm{Fe}$ & $\mathrm{Cu}$ & $\mathrm{Mn}$ & $\mathrm{Mg}$ & $\mathrm{Zn}$ & $\mathrm{Ti}$ & $\mathrm{Al}$ \\
\hline A356 & 6.80 & 0.19 & 0.003 & 0.001 & 0.30 & 0.011 & 0.0008 & Rem \\
A356+Ti & 6.85 & 0.18 & 0.003 & 0.001 & 0.30 & 0.011 & 0.0042 & Rem \\
\hline
\end{tabular}
crucible of the $\mathrm{A} 50$
Fig. 1 Dimensions for the

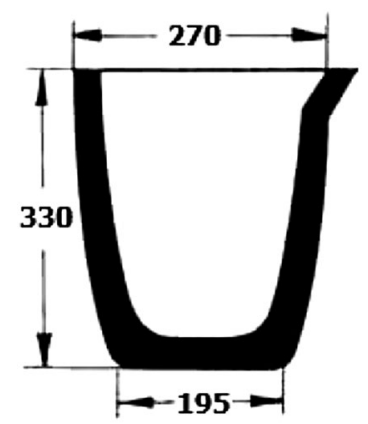

An electric furnace that is $50 \mathrm{~kW}$ was used and the charge was melted in an $\mathrm{A} 50 \mathrm{SiC}$ crucible at $740^{\circ} \mathrm{C}$. The dimension of the crucible is shown in Fig. 1. The crucible has $22 \mathrm{~kg}$ aluminum capacity. Each casting was achieved with about $2 \mathrm{~kg}$ alloy which is on top of the melt. After the melting temperature was reached, the AITi5B1 grain refiner was added to achieve $30 \mathrm{ppm}$ [37]. The chemical composition of the liquid alloy after AITi5B1 addition was given in Table 1. Reduced Pressure Test (RPT) samples were collected at $20 \mathrm{~min}$ of the time interval and ten tensile test bars were produced in a single mold (Fig. 2). Tensile test samples were machined according to the ASTM B557 standard (Fig. 3). The tensile tests were completed according to TS EN ISO 6892-1 standard by using a Shimadzu machine that has $250 \mathrm{kN}$ capacity.

Reduced pressure test samples were sectioned from the centre and cross-section was subjected to image analysis (SigmaScan) in order to measure the bifilm index. In order to obtain the bifilm index, all porosities on the sectioned surface were scanned, and then the scanned surfaces were uploaded to the analysis program. In the next stage, all porosities were automatically marked, and the total length of them was calculated in $\mathrm{mm}$. Minitab was used for the statistical analysis of both bifilm index and tensile test results. Scanning Electron Microscopy (SEM) analyses were done on the fracture surface of tensile test samples to examine oxide structure.

\section{Result and discussion}

It has been shown that the main factor in the formation of porosity is the entrainment of the surface oxide film $\left(\mathrm{Al}_{2} \mathrm{O}_{3}\right)$ into the liquid. Thus, the bifilm index has to be measured to quantify the melt quality.
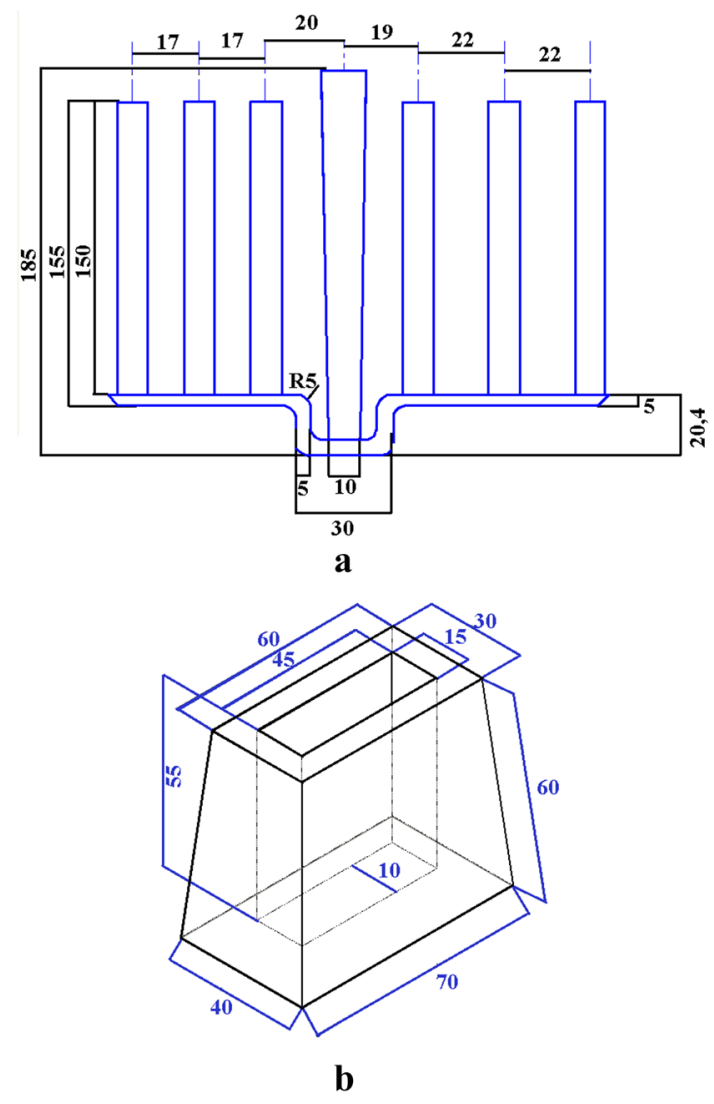

Fig. 2 Dimension of moulds a Tensile test, $\mathbf{b}$ RPT

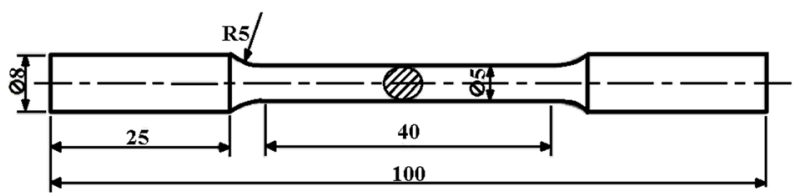

a

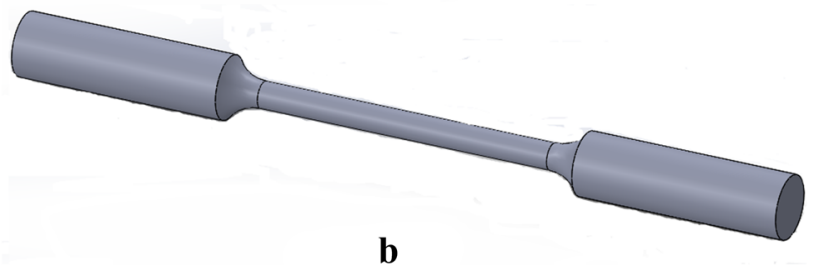

Fig. 3 a Dimensions for the tensile test sample, $\mathbf{b}$ solid image of the tensile test sample 
Representative images of seven RPT samples obtained after consequent 20 min were given in Fig. 4 . As can be seen, the size and number of bifilms changed with time after Ti addition. The trend appeared to be decreasing as holding time was increased. It can be seen that at time zero (Fig. 4a), which represents the initial bifilm content of the raw material, the bifilms were large and in high in population. When Ti was added, after 20 min of holding (Fig. 4b), it can be seen that there was a significant decrease in the number and size of bifilms. After 20 more minutes (Fig. 4c-g), the presence of these bifilms was further reduced. The visual observations seen in Fig. 4 were numerically analyzed and the results were presented in Fig. 5.

Figure 5a clearly shows that the bifilm index decreased exponentially after $\mathrm{Ti}$ addition with increased holding time. From the viewpoint of the bifilm index value, it was understood that the optimum holding time may be $40 \mathrm{~min}$ after $\mathrm{Ti}$ addition. When the results of the lognormal distribution of bifilm index results were examined (Fig. 5b), it can be said that the average bifilm length value decreases after 40 min depending on the time and increased after $40 \mathrm{~min}$. While it can be seen from Fig. $5 \mathrm{~b}$ that the bifilm dimensions were closer to each other in the low holding times, that is, they had more homogeneous distribution in terms of size. In the long holding times, this distribution was diverted from homogeneity and the bifilms were seen to exist in many variable dimensions. Figure $5 c$ shows that the number density of the bifilm index decreased exponentially with time. This result associated with Fig. $5 \mathrm{~b}$ suggested the conclusion that the change of the number of bifilms gained stability while the dimensions of bifilms varied too much.

It is known that grain refiner master alloys are added to the liquid metal in order to obtain a finer grain and reduce porosity formation structure by regulating the microstructure [1, 20, 38, 39]. The optimum secondary dendrite arm space (SDAS) and micro-porosity are obtained by $0.06-0.15 \%$ Ti grain refiner addition [40]. It is claimed that the titanium-containing grain refiners collapse to the bottom due to the density difference and the oxide films (bifilms) are precipitated during this collapse [41, 42]. On the other hand, it is recommended that the casting process be made quickly in grain refinement processes performed with Ti-containing master alloys [18]. Because, due to the high density of titanium, it gradually collapses at the bottom and the grain refiner loses its effect. Through this theoretical information $[13,36]$ and the results of the experimental work carried out in this study, the effect of grain refiners on porosity formation was schematically presented in Fig. 6. Figure $6 \mathrm{a}$ is for before Ti addition and b, c, d, e, f and g represent 20, 40,60, 80, 100 and 120 min. after $\mathrm{Ti}$ addition, respectively. The seven different images a-g given in Fig. 6 shows how changing oxide films in the liquid for casting with time are shown and the role of titanium in this change. Titanium-containing grain refiners, depending on the time, collapses at the bottom and they also lead bifilms concomitantly and improve the casting quality by reducing porosity formation. The positive effect of titanium on porosity formation continues as long as it continues to act on grain refinement. For the experimental conditions carried out in this study, the activity of the titanium increased exponentially up to $40 \mathrm{~min}$ and reached its maximum activity at $40 \mathrm{~min}$. However, after $40 \mathrm{~min}$, the $\mathrm{Ti}$ effect continued to increase by decreasing depending on time. This finding can be clearly seen in the bifilm index results and also in the mechanical property findings given in Fig. 7. The effect of titanium on the time-dependent mechanical properties (UTS, YS, elongation and toughness) was presented in detail in Fig. 7. If the graphs given are evaluated in general, the improvement of mechanical properties with time can be easily stated. It is clear that the most effective holding time in the liquid state was $40 \mathrm{~min}$ on the UTS graph, besides similar findings were obtained in all graphs. On the other hand, it is mentioned in the literature [43] that $\mathrm{TiB}_{2}$ is attributed to the nucleation of $a$ on $\beta$. However, in another study [44], it is claimed that $\mathrm{TiB}_{2}$ has no nucleation effect on a-Al grains in pure aluminum. In the current study, it was focused on the effect of $\mathrm{TiB}_{2}$ on porosity formation rather than the effect of it on

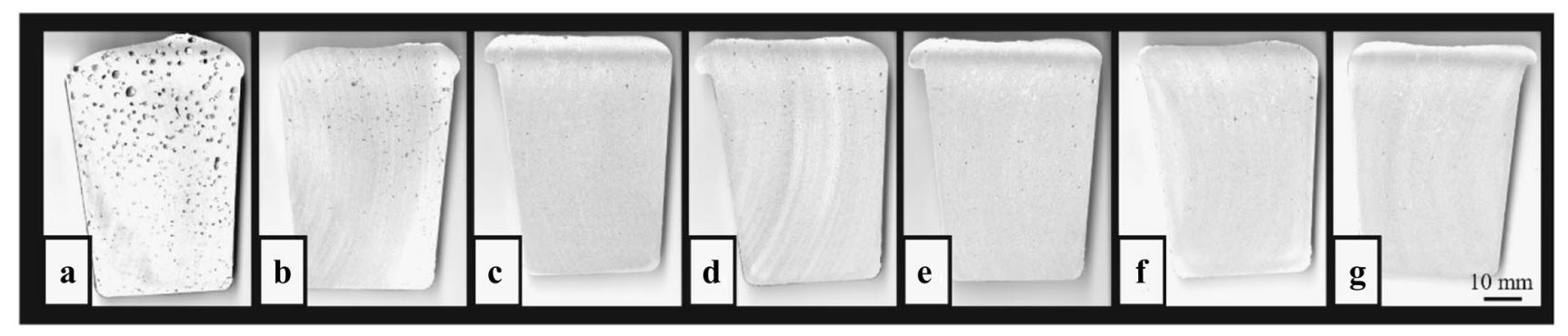

Fig. 4 Representative images of RPT samples collected at different time intervals; a 0 min., b 20 min., c 40 min., d 60 min., e 80 min., f $100 \mathrm{~min}$. and $\mathbf{g} 120 \mathrm{~min}$ 


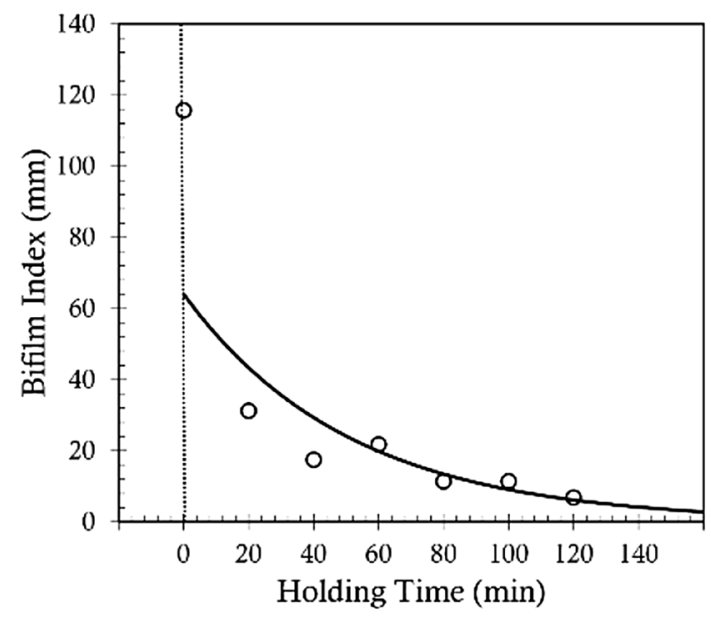

a

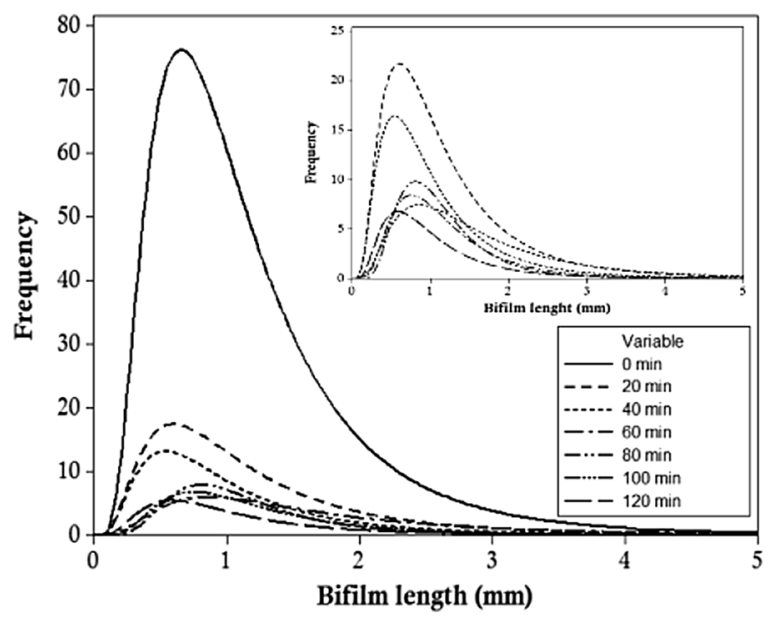

b

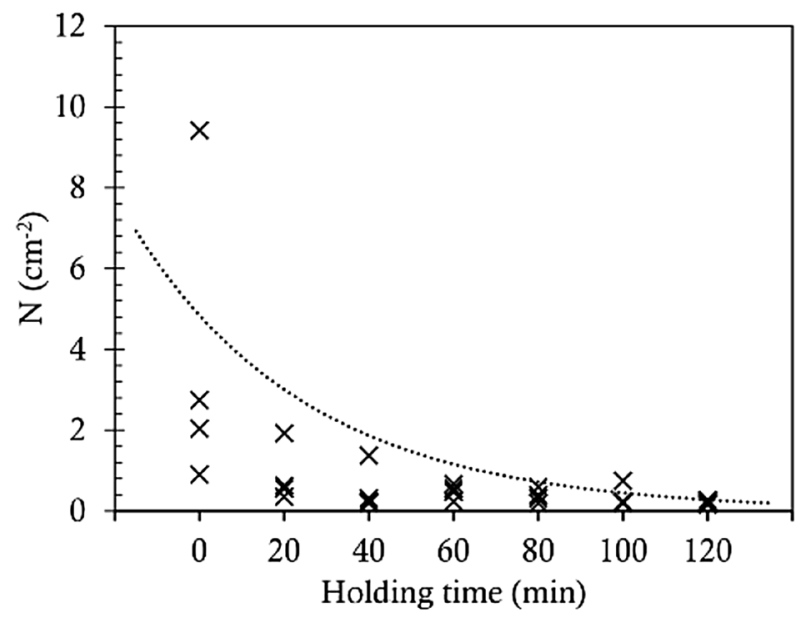

c

Fig. 5 a Bifilm index versus holding time of liquid aluminium, $\mathbf{b}$ distribution of bifilm length, $\mathbf{c}$ number density of bifilms

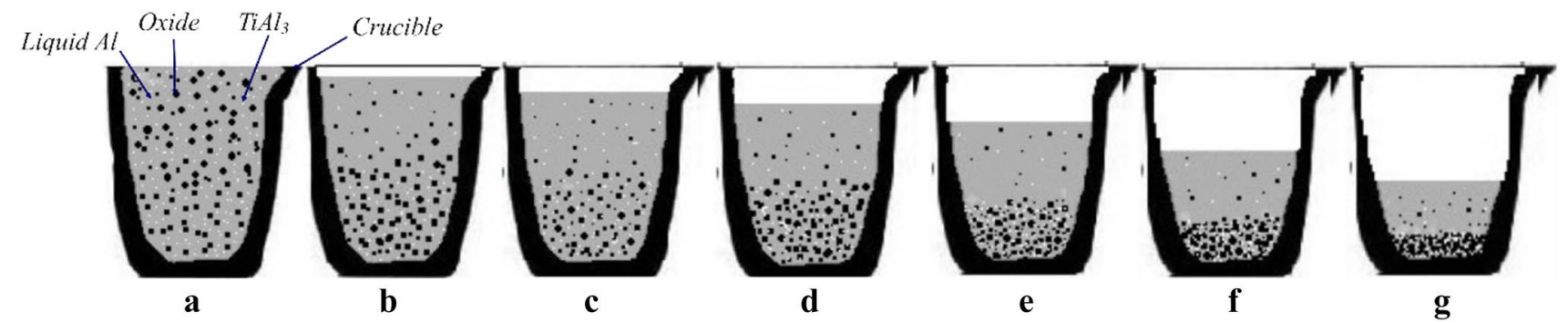

Fig. 6 Schematic representation of the effect of Ti addition on melt quality

microstructure. From the result of the experimental study, It can be concluded that $\mathrm{TiB}_{2}$ is also attributed to decrease porosity with a mechanism which is collapses from the top to bottom of the melt depending on time.

Weibull analysis can be used to investigate mechanical properties statically. This analysis can be applied using two equations. The first equation is the Hazen method and the second is Weibull analysis $[23,45,46]$. These two equations were given below:

$P=(i-0.5) / n$ 


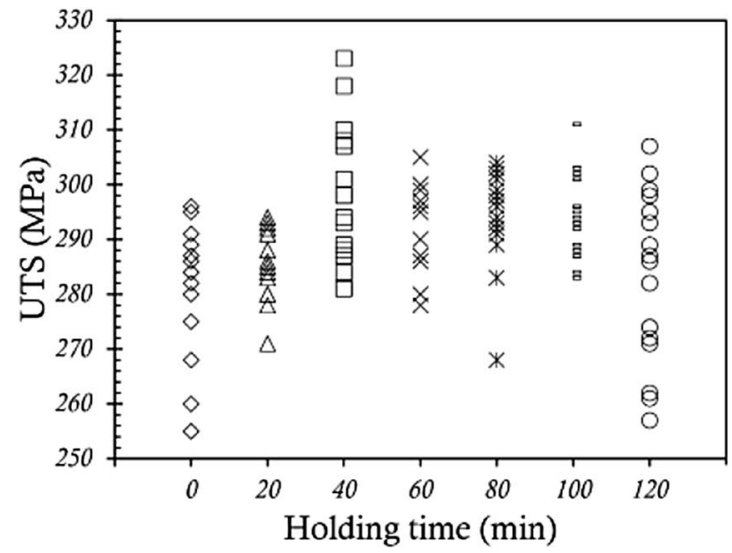

a

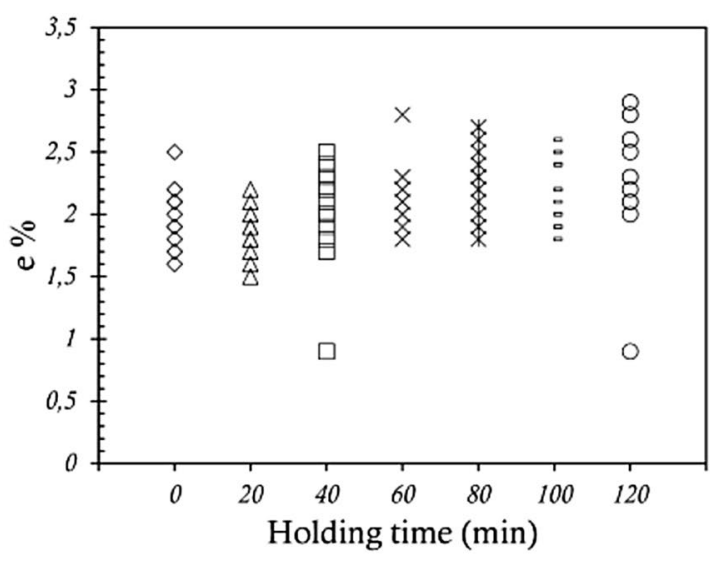

c

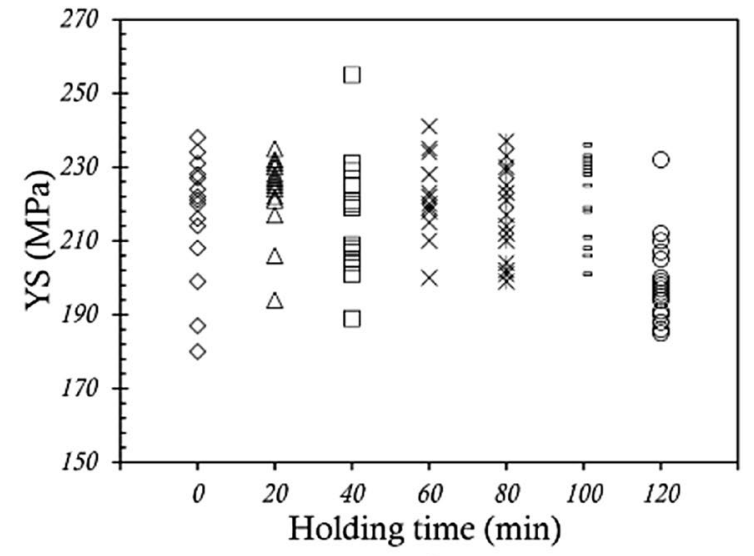

b

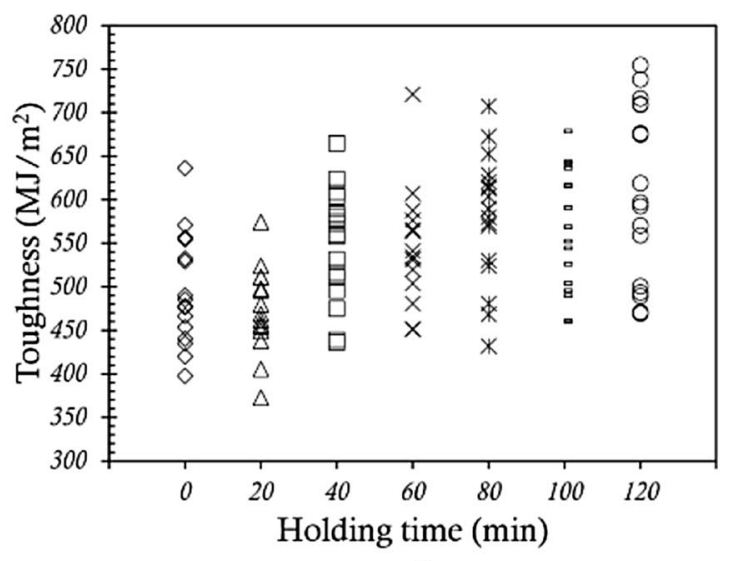

d

Fig. 7 Changes in mechanical properties depending on holding time. a Ultimate Tensile Strength (UTS), b Yield Strength (YS), c Elongation $\%$ (e) and d Toughness

where I; Numbering figures, $\mathrm{n}$; Total numbering, and $\mathrm{p}$; possibility

$W=\ln (\ln (1 /(1-p)))$

The Weibull analysis presents the reliability and repeatability of experimental results. Weibull modulus can be used for Weibull analysis. If the Weibull modulus is high of a parameter, the parameter is more reliable than other parameters [10]. Characteristic alpha gives an estimating data with $63 \%$ possibility. The result of the characteristic alpha calculation can be had in a study that is done under the same conditions [4, 23].

The Weibull analysis was performed on all mechanical test results) and the results were summarized in Fig. 8 and Table 2 for Weibull modulus and characteristic alpha respectively. According to Fig. 8, the highest repeatability for UTS, elongation and toughness was obtained in $20 \mathrm{~min}$ with the highest shape parameter. The lowest value was found for $120 \mathrm{~min}$ of holding. For $40 \mathrm{~min}$, the level of repeatability seems to be acceptable.

It can be said that the highest UTS value for the experimental conditions used in this study can be obtained at a holding time of $40 \mathrm{~min}$ as $304 \mathrm{MPa}$. These characteristic alpha values were $228 \mathrm{MPa}$ yield stress at $20 \mathrm{~min}, 2.63 \%$ elongation at fracture at $120 \mathrm{~min}$ and $639 \mathrm{MJ} / \mathrm{m}^{2}$ toughness at $120 \mathrm{~min}$. The UTS results increased with time and decreased in $120 \mathrm{~min}$, and the highest value was obtained in 40 min of holding time. It was also shown in this graph that the elongation values increased with time, the lowest value was seen in 20 min holding time, and the maximum value was obtained in 120 min holding time.

Since bifilms are the main source of porosity formation and degradation of mechanical properties, a correlation between bifilm index and mechanical properties were also carried out. It has been mentioned by many researchers $[1,5,12,17,32,47-51]$ that the number, size, distribution 


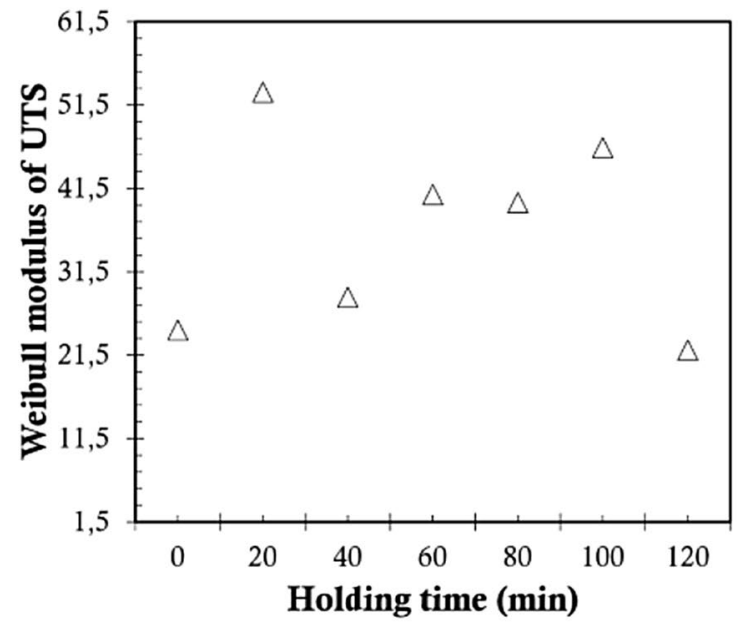

a

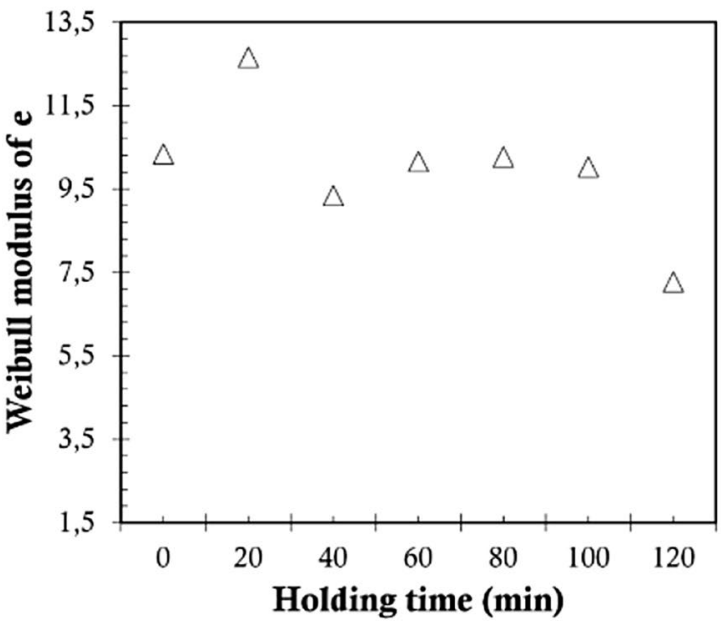

c

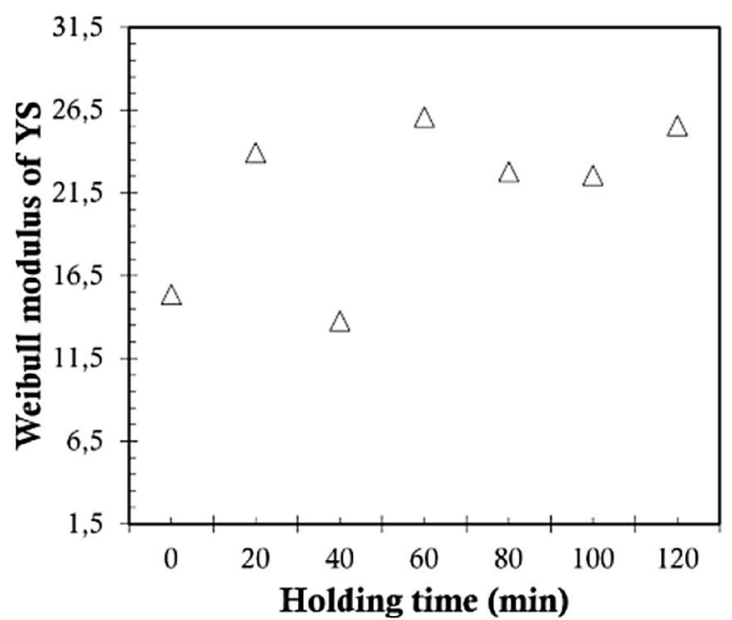

b

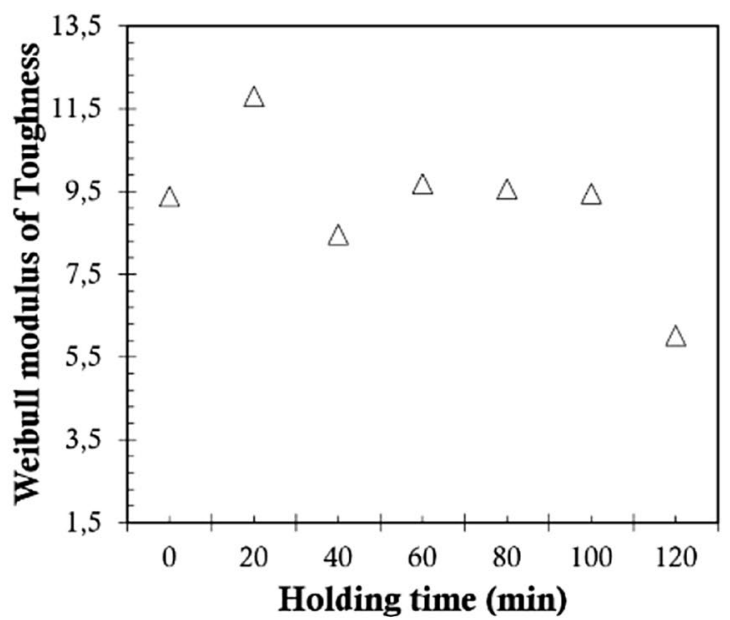

d

Fig. 8 Change in Weibull modulus of the mechanical properties depending on holding time

Table 2 Result of characteristic alpha of the mechanical properties depending on holding time

\begin{tabular}{lllll}
\hline \multirow{2}{*}{ Holding time } & \multicolumn{4}{l}{ Characteristic alpha (scale) } \\
\cline { 2 - 5 } & UTS & YS & e & Toughness \\
\hline 0 & 285.77 & 224.67 & 2.09 & 521.7 \\
20 & 288.9 & 228.79 & 1.94 & 495.47 \\
40 & 304.11 & 221.34 & 2.25 & 576.34 \\
60 & 294.97 & 226.85 & 2.23 & 572.84 \\
80 & 298.67 & 222.53 & 2.38 & 611.05 \\
100 & 297.67 & 226.58 & 2.3 & 594.15 \\
120 & 290.91 & 201.16 & 2.63 & 639.82 \\
\hline
\end{tabular}

and orientations of bifilms should be evaluated when discussing the effect of bifilms on mechanical properties and casting quality. Bifilms (oxide structures) imaged from the samples of the study were presented in Fig. 9.
Basing on these studies, lognormal distribution graphs were drawn on each mechanical property for experimental findings and given in Fig. 10. When the lognormal graph of the UTS results was examined, it was seen that the distributions belonging to the casting with 40 min holding time which had the highest value were in a wider range than the casting with 20 min, that is, the values belonging to the casting with 20 min holding time were closer to each other. Looking at the results after $40 \mathrm{~min}$, it appeared that the values started to fall and took place in much wider scatter. The fact that the widest scattering occurs after 120 min of holding and that it was much more scattered than the zero-minute holding parameter shows that time-dependent new bifilms are carried out in the liquid metal. A similar effect was seen in other results. However, in the yield strength, this effect was visible on the average value contrary to the distributions. Although the highest value was obtained at the 120 min holding time, the most 
Fig. 9 Representative SEM images of oxide structures (bifilms) on the fracture surface of tensile bars. a Oxide structures from the samples of zero minute holding time, b Surface oxides from the samples of zero minute holding time, $c$ Oxides between dendrite arms from the samples of $20 \mathrm{~min}$ holding time, $\mathbf{d}$ Surface oxides from the samples of $40 \mathrm{~min}$ holding time, e An oxide on the dendrite arms from the samples of $40 \mathrm{~min}$ holding time, $f$ Oxides from the samples of 120 min holding time
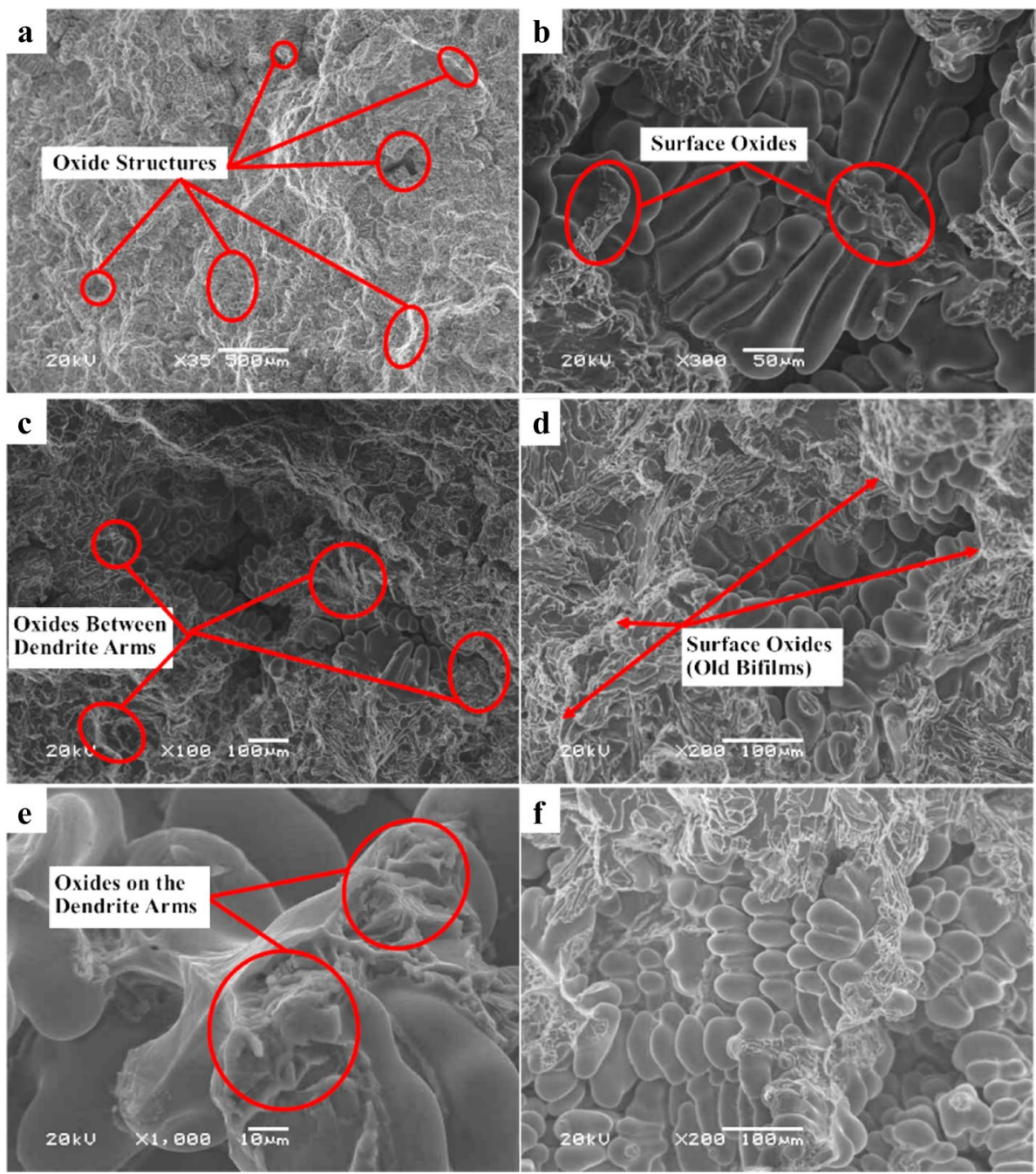

scattered values were observed in this casting parameter. In the elongation results, the lognormal distributions of the 40 min castings reflected the effect of titanium addition. This is because the elongation has increased compare to zero-minute holding time and all values are in a very narrow range. This effect was partly presented also in the results of toughness.

A critical evaluation of the optimum holding time for a high-quality casting can be made using all experimental results. When results of bifilm calculations, mechanical properties and statistical analysis are taking into account together, it can be said that casting quality tends to increase up to $60 \mathrm{~min}$ holding time. However, once reproducibility of the castings is considered, the optimum holding time appears as $40 \mathrm{~min}$. Shortly, it can be concluded that $40 \mathrm{~min}$ is acceptable as the optimum time limit, and after this holding time, casting quality can be decreased as time goes up.

From the results of the statistical analysis carried out, it was examined whether there is any relation between the average bifilm index and toughness, or not, and the attained result was given graphically in Fig. 11. As can be seen clearly from the graph, the bifilm dimensions seriously affected the toughness values of this alloy. As the average index increased, the toughness value increased. In the case of such an effect, it was considered that the existence of a low number of bifilms and very different distributions occurred at high average bifilm index values. And these variables were thought to be effective on toughness. On the other hand, the relationship between the bifilm index (casting quality) and UTS was also examined, and the results were presented in Fig. 12. From these findings, it can be said that there was a strong correlation between the bifilm index and UTS. However, the effect of casting quality on UTS depends on how big and small the bifilm index value is. As the bifilm index increased, that is, as the casting quality decreased, the UTS decreased. This conclusion can be clearly seen in Fig. 12. On the other hand, when the Bifilm index values were low, the UTS values were in

\section{SN Applied Sciences}




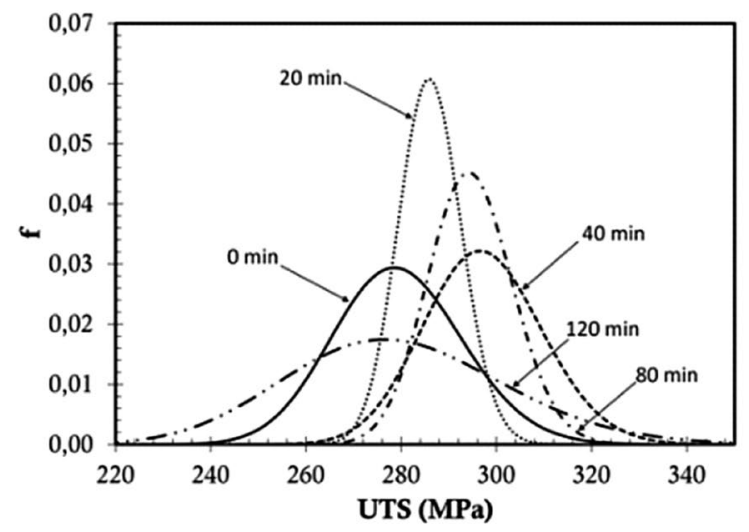

a

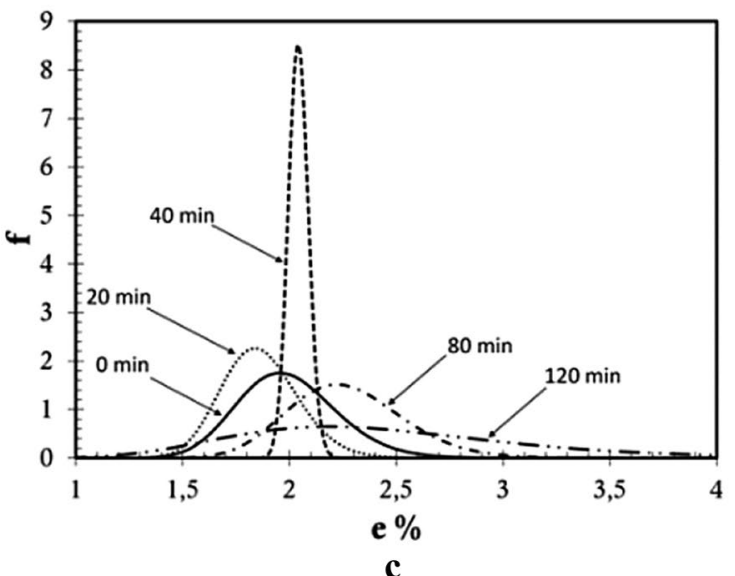

c

Fig. 10 Lognormal distribution of results of mechanical properties

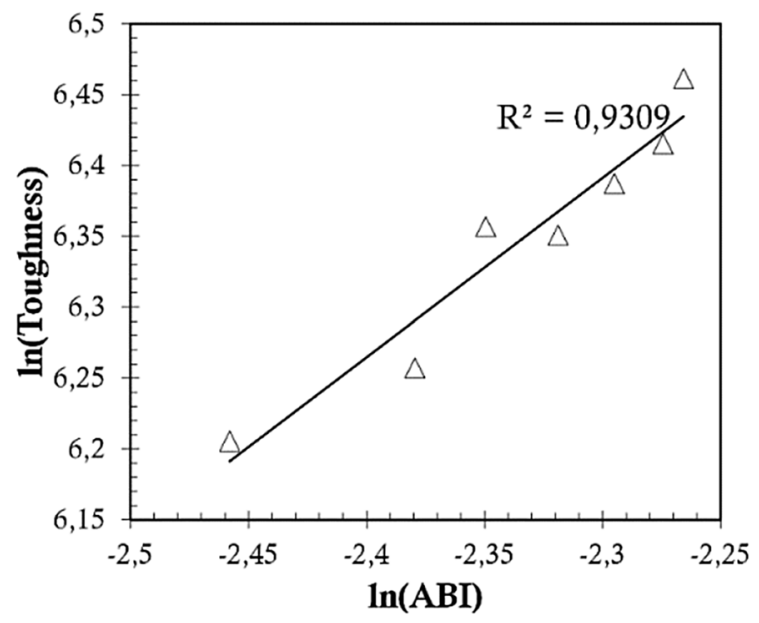

Fig. 11 The relationship between average bifilm index (ABI) and toughness

a very wide range, UTS was in the narrow range at high Bifilm index values. This is because the casting defects (bifilms and porosities) present in the material at a high bifilm index value were likely to reduce the UTS results.

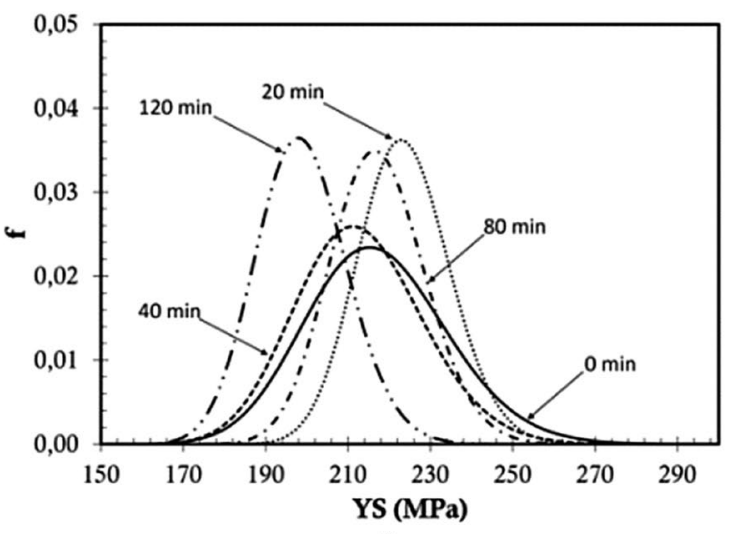

b
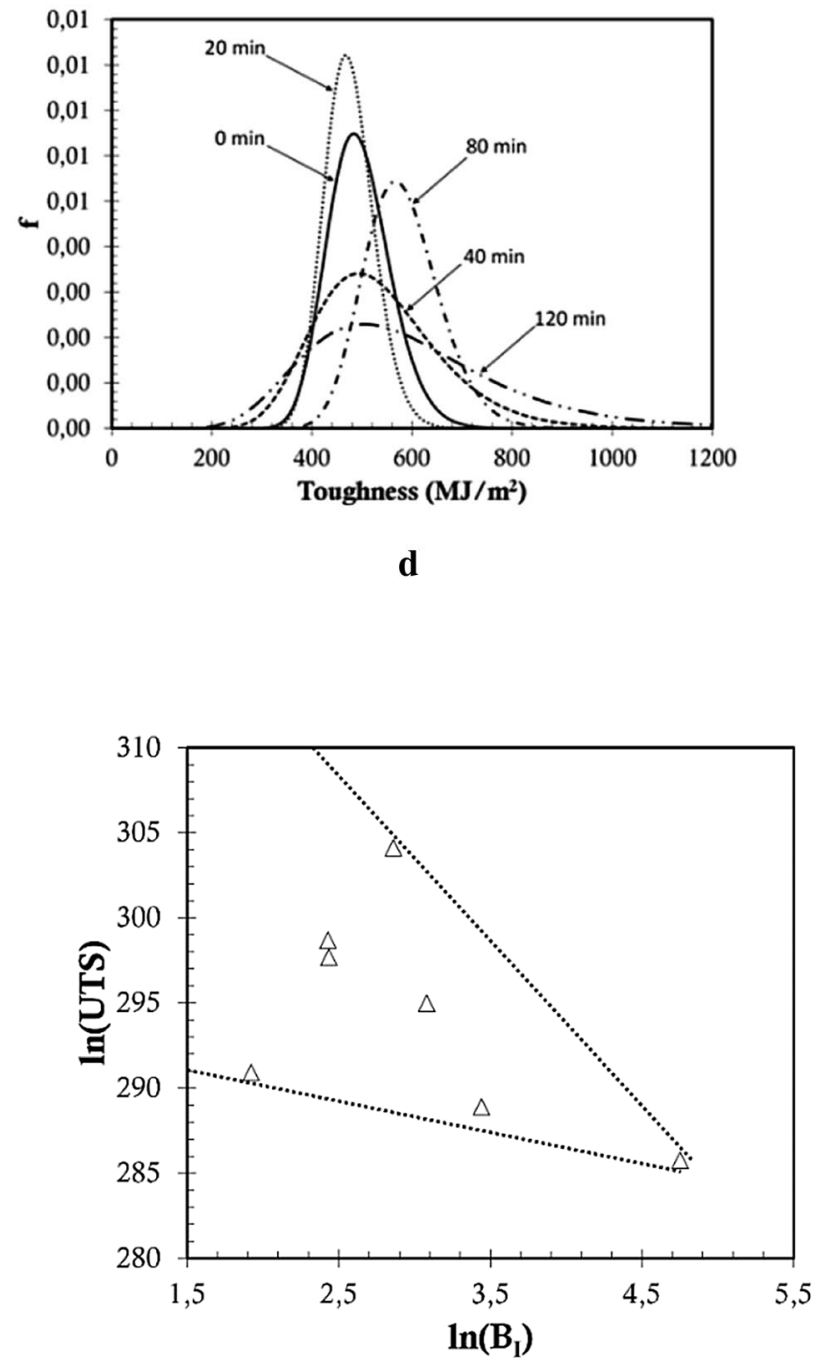

Fig. 12 The relationship between bifilm index $\left(B_{l}\right)$ and UTS

In other words, the more bifilm present in the material, the more likely it will act as a crack to decrease the mechanical properties. 


\section{Conclusion}

This study has been carried out in order to investigate the effect of holding time on bifilms after the addition of titanium. The conclusions from the study can be listed as follow;

1. Ti addition significantly decreases the bifilms in the liquid metal as Ti collects oxides when it moves to the bottom of the crucible after addition, and the number of bifilms is reduced as holding time increases.

2. New bifilms are generated as the holding time of the liquid metal is increased.

3. The size of the bifilms considerably affects the toughness of $A 356$. As the average bifilm index increases, toughness increases.

4. There is a strong correlation between the bifilm index and UTS. A high population of bifilms decreases mechanical properties. Also, the elongation value at fracture is increased as the holding time increases.

5. The melt can be held a maximum of $60 \mathrm{~min}$ after Ti addition and the optimum holding time may be 40 min to obtain the highest quality in A356 casting.

Acknowledgements The authors would like to thank John Campbell and Derya Dispinar for their advice about the effect of Ti on the casting quality and mechanical properties of Al alloys.

\section{Compilance with ethical standards}

Conflict of interest The authors declare that they have no conflict of interest.

\section{References}

1. Campbell J (2006) An overview of the effects of bifilms on the structure and properties of cast alloys. Metall Mater Trans B 37:857-863. https://doi.org/10.1007/BF02735006

2. Campbell J, Tiryakioğlu M (2010) Review of effect of $P$ and Sr on modification and porosity development in Al-Si alloys. Mater Sci Technol 26:262-268. https://doi.org/10.1179/17432 8409X425227

3. Dispinar D, Campbell J (2011) Porosity, hydrogen and bifilm content in Al alloy castings. Mater Sci Eng, A 528:3860-3865. https://doi.org/10.1016/j.msea.2011.01.084

4. Eisaabadi BG, Davami P, Kim SK, Tiryakioğlu M (2013) The effect of melt quality and filtering on the Weibull distributions of tensile properties in $\mathrm{Al}-7 \% \mathrm{Si}-\mathrm{Mg}$ alloy castings. Mater Sci Eng: A 579:64-70. https://doi.org/10.1016/j.msea.2013.05.014

5. Eisaabadi Bozchaloei G, Varahram N, Davami P, Kim SK (2012) Effect of oxide bifilms on the mechanical properties of cast $\mathrm{Al}-7 \mathrm{Si}-0.3 \mathrm{Mg}$ alloy and the roll of runner height after filter on their formation. Mater Sci Eng, A 548:99-105. https://doi. org/10.1016/j.msea.2012.03.097
6. Mostafaei $M$, Ghobadi $M$, Eisaabadi BG, Uludağ $M$, Tiryakioğlu $M$ (2016) Evaluation of the effects of rotary degassing process variables on the quality of A357 aluminum alloy castings. Metall Mater Trans B 47:3469-3475. https://doi.org/10.1007/s1166 3-016-0786-7

7. Tiryakioğlu M, Campbell J, Alexopoulos ND (2009) On the ductility of cast Al-7 Pct Si-Mg alloys. Metall Mater Trans A 40:1000. https://doi.org/10.1007/s11661-008-9762-4

8. Haghayeghi R, Bahai $H$, Kapranos P (2012) Effect of ultrasonic argon degassing on dissolved hydrogen in aluminium alloy. Mater Lett 82:230-232. https://doi.org/10.1016/j.matle t.2012.05.112

9. Shabestari S, Miresmaeili S, Boutorabi S (2003) Effects of Srmodification and melt cleanliness on melt hydrogen absorption of 319 aluminium alloy. J Mater Sci 38:1901-1907. https://doi. org/10.1023/A:1023592111481

10. Dispinar D, Campbell J (2004a) Critical assessment of reduced pressure test. Part 1: porosity phenomena. Int J Cast Met Res 17:280-286. https://doi.org/10.1179/136404604225020696

11. Dispinar D, Campbell J (2004b) Critical assessment of reduced pressure test. Part 2: quantification. Int J Cast Met Res 17:287294. https://doi.org/10.1179/136404604225020704

12. Dispinar D, Campbell J (2006) Use of bifilm index as an assessment of liquid metal quality. Int J Cast Met Res 19:5-17. https:// doi.org/10.1179/136404606225023300

13. Campbell J (2015) Complete casting handbook: metal casting processes, metallurgy, techniques and design. ButterworthHeinemann, Oxford, UK

14. Staley JT, Tiryakioğlu M, Campbell J (2007) The effect of hot isostatic pressing (HIP) on the fatigue life of A206-T71 aluminum castings. Mater Sci Eng, A 465:136-145. https://doi. org/10.1016/j.msea.2007.02.009

15. Uludağ $M$, Çetin $R$, Dispinar $D$ (2018) Freezing range, melt quality and hot tearing in Al-Si alloys-unpublished work, 49, pp. 1948-1961.https://doi.org/10.1007/s11661-018-4512-8

16. Pandee P, Gourlay CM, Belyakov SA, Patakham U, Zeng G, Limmaneevichitr C (2018) AISi2Sc2 intermetallic formation in Al-7Si-0.3Mg-xSc alloys and their effects on as-cast properties. J Alloy Compd 731:1159-1170. https://doi.org/10.1016/j.jallc om.2017.10.125

17. Uludağ $M$, Gemi L, Çetin R, Dispinar D (2015) The effect of holding time and solidification rate on porosity of $A 356$. Pamukkale Univ Muh Bilim Derg 21:348-351. https://doi.org/10.5505/pajes .2015 .59932

18. Campbell J (2004) Castings practice: the ten rules of castings. Butterworth-Heinemann, Oxford, UK

19. Dispinar D, Akhtar S, Nordmark A, Di Sabatino M, Arnberg L (2010) Degassing, hydrogen and porosity phenomena in $A 356$. Mater Sci Eng, A 527:3719-3725. https://doi.org/10.1016/j. msea.2010.01.088

20. Samuel AM, Doty HW, Valtierra S, Samuel FH (2017a) Porosity formation in $\mathrm{Al}-\mathrm{Si}$ sand mold castings. Int J Metalcasting 11:812-822. https://doi.org/10.1007/s40962-016-0129-0

21. Sigworth $G$ (2011) Understanding quality in aluminum castings. Int J Metalcasting 5:7-22. https://doi.org/10.1007/bf03355504

22. Yorulmaz A, Yüksel Ç, Erzi E, Dispinar D (2016) In shape casting: 6th international symposium. Springer

23. Tiryakioğlu M, Campbell J (2010) Weibull analysis of mechanical data for castings: a guide to the interpretation of probability plots. Metall Mater Trans A 41:3121-3129. https://doi. org/10.1007/s11661-010-0364-6

24. Tiryakioğlu $M$, Hudak $D$ (2007) On estimating Weibull modulus by the linear regression method. J Mater Sci 42:10173-10179. https://doi.org/10.1007/s10853-007-2060-5

25. Zahedi H, Emamy M, Razaghian A, Mahta M, Campbell J, Tiryakioğlu M (2007) The effect of Fe-rich intermetallics on the 
Weibull distribution of tensile properties in a cast Al-5 pct Si-3 pct Cu-1 pct Fe-0.3 pct Mg alloy. Metall Mater Trans A 38:659670. https://doi.org/10.1007/s11661-006-9068-3

26. De Giovanni M, Warnett JM, Williams MA, Srirangam P (2017) 3D imaging and quantification of porosity and intermetallic particles in strontium modified Al-Si alloys. J Alloy Compd 727:353-361. https://doi.org/10.1016/j.jallcom.2017.08.146

27. Li Q, Li F, Xia T, Lan Y, Jian Y, Tao F (2015) Effects of in-situ $Y$-Al2O3 particles and heat treatment on the microstructure and mechanical properties of A356 aluminium alloy. J Alloy Compd 627:352-358. https://doi.org/10.1016/j.jallcom.2014.11.212

28. Song J, Xiong S-M, Li M, Allison J (2009) The correlation between microstructure and mechanical properties of high-pressure die-cast AM50 alloy. J Alloy Compd 477:863-869. https://doi. org/10.1016/j.jallcom.2008.11.040

29. Mohanty P, Gruzleski J (1996) Grain refinement mechanisms of hypoeutectic Al-Si alloys. Acta Mater 44:3749-3760. https://doi. org/10.1016/1359-6454(96)00021-3

30. Dahle AK, Tøndel PA, Paradies CJ, Arnberg L (1996) Effect of grain refinement on the fluidity of two commercial Al-Si foundry alloys. Metall Mater Trans A 27(8):2305-2313. https:// doi.org/10.1007/BF02651885

31. Akhtar S, Arnberg L, Di Sabatino M, Dispinar D, Syvertsen M (2009) A comparative study of porosity and pore morphology in a directionally solidified A356 alloy. Int J Metalcast 3:39-52. https://doi.org/10.1007/bf03355440

32. Uludağ $M$, Dispinar $D$ (2017) Assessment of mechanism of pore formation in directionally solidified A356 alloy. Arch Foundry Eng 17:157-162. https://doi.org/10.1515/afe-2017-0029

33. Jiang W, Fan Z, Dai Y, Li C (2014) Effects of rare earth elements addition on microstructures, tensile properties and fractography of A357 alloy. Mater Sci Eng, A 597:237-244. https://doi. org/10.1016/j.msea.2014.01.009

34. Jiang W, Fan Z, Liu D, Dong X, Wu H, Wang HS (2012) Effects of process parameters on internal quality of castings during novel casting. Mater Manuf Process 28:48-55. https://doi. org/10.1080/10426914.2012.681414

35. Zhu J, Jiang W, Li G, Guan F, Yu Y, Fan Z (2020) Microstructure and mechanical properties of SiCnp/Al6082 aluminum matrix composites prepared by squeeze casting combined with stir casting. J Mater Process Technol. https://doi.org/10.1016/j.jmatp rotec.2020.116699

36. Campbell J, Dispinar D (2015) Effect of Ti on the melt quality of Al alloys, Personal communication

37. Di Sabatino M, Arnberg L (2005) Effect of grain refinement and dissolved hydrogen on the fluidity of A356 alloy. Int J Cast Met Res 18:181-186. https://doi.org/10.1179/136404605225022982

38. Samuel AM, Doty HW, Valtierra S, Samuel FH (2017b) A metallographic study of grain refining of Sr-modified 356 alloy. Int J Metalcasting 11:305-320. https://doi.org/10.1007/s4096 2-016-0075-x
39. Węglowski M, Dymek S (2012) Microstructural modification of cast aluminium alloy AISi9Mg via friction modified processing. Arch Metall Mater 57:71-78. https://doi.org/10.2478/v1017 2-011-0155-0

40. Lee C (2016) Effect of Ti-B addition on the variation of microporosity and tensile properties of A356 aluminium alloys. Mater Sci Eng, A 668:152-159. https://doi.org/10.1016/j.msea.2016.05.059

41. Schaffer PL, Dahle AK, Zindel JW (2004) Grain refiner fade in aluminium alloys. TMS Light Met 821-826

42. Sigworth GK, Kuhn TA (2007) Grain refinement of aluminum casting alloys. Int J Metalcast 1:31-40. https://doi.org/10.1007/ bf03355416

43. Gosslar D, Günther R, Hecht U, Hartig C, Bormann R (2010) Grain refinement of TiAl-based alloys: the role of TiB2 crystallography and growth. Acta Mater 58:6744-6751. https://doi. org/10.1016/j.actamat.2010.08.040

44. Iqbal N, Van Dijk N, Hansen T, Katgerman L, Kearley G (2004) The role of solute titanium and TiB2 particles in the liquid-solid phase transformation of aluminum alloys. Mater Sci Eng, A 386:20-26. https://doi.org/10.1016/j.msea.2004.06.068

45. Tunçay T, Bayoğlu S (2017) The effect of iron content on microstructure and mechanical properties of A356 cast alloy. Metall Mater Trans B 48:794-804. https://doi.org/10.1007/s1166 3-016-0909-1

46. Yüksel Ç (2019) Weibull analysis of fluidity and hardness of ultrasonically degassed secondary Al7SiO. $3 \mathrm{Mg}$ aluminum alloy. China Foundry 16:352-357. https://doi.org/10.1007/s4123 0-019-9029-2

47. Uludağ $M$, Çetin R, Dispinar D, Tiryakioğlu M (2017) Characterization of the effect of melt treatments on melt quality in $\mathrm{Al}-7 \mathrm{wt} \%$ Si-Mg alloys. Metals 7:157. https://doi.org/10.3390/met7050157

48. Uludağ $M$, Çetin R, Dişpinar D, Tiryakioğlu M (2018) On the interpretation of melt quality assessment of A356 aluminum alloy by the reduced pressure test: the bifilm index and its physical meaning. Int J Metalcast. https://doi.org/10.1007/s4096 2-018-0217-4

49. Uludağ M, Gemi L, Çetin R, Dispinar D (2016) The effect of holding time and solidification rate on porosity of A356. Am J Eng Res 5:271-275

50. Uludağ $M$, Gemi L, Dispinar D (2016) Efficiency of Sr modification in hypereutectic Al-Si alloys. Int J Sci Tech Res Eng 1:21-26

51. Uludağ $M$, Yazman Ş, Bakırcıoğlu B, Dışpınar D (2015) The effect of Si morphology on machinability of Al-Si alloys. Pamukkale Univ Muh Bilim Derg 21:381-385. https://doi.org/10.5505/pajes .2015 .66933

Publisher's Note Springer Nature remains neutral with regard to jurisdictional claims in published maps and institutional affiliations. 